\title{
Aromatic Characterisation of Malvasia Odorosissima Grapevines and Comparison with Malvasia di Candia Aromatica
}

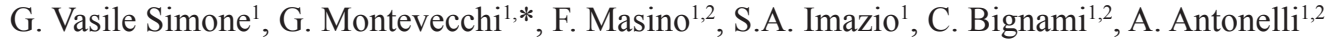 \\ (1) Interdepartmental Centre BIOGEST - SITEIA, University of Modena and Reggio Emilia, Piazzale Europa 1, 42124 Reggio \\ Emilia, Italy \\ (2) Department of Life Science (Agri-Food Science Area), University of Modena and Reggio Emilia, Via G. Amendola 2 \\ (Padiglione Besta), 42122 Reggio Emilia, Italy
}

Submitted for publication: July 2017

Accepted for publication: October 2017

Keywords: Malvasia di Candia aromatica, Malvasia odorosissima, aromatic wine grapes, SPE-GC-MS approach, aroma compounds, rose oxide isomers

\begin{abstract}
Malvasia odorosissima is an aromatic grapevine (Vitis vinifera L., 1753) variety that is often confused with Malvasia di Candia aromatica (Vitis vinifera L., 1753), despite the genetic information now available on the pedigree and genetic relationships linking the two varieties. In an effort to offer a contribution to fill this gap, also from an aromatic point of view, free and glycosylated aroma compounds were determined using the SPE extraction method, followed by GC-MS analysis in two consecutive vintages. The results have for the first time provided the aromatic characterisation of Malvasia odorosissima. Geraniol and its derivatives were the most abundant set of volatiles. In contrast to Malvasia di Candia aromatica and the other aromatic varieties, Malvasia odorosissima showed a very small amount of glycosylated volatiles, thus expressing its aromatic potential almost completely. The abundance of free terpenoids in the aromatic profile of Malvasia odorosissima, even higher than in Malvasia di Candia aromatica, is a main feature for the oenological exploitation of this variety, which is on the brink of extinction. In addition, the presence of rose oxides, found solely in Malvasia odorosissima, renders its aromatic profile more similar to that of White Muscat. This result is consistent with the parent-offspring relationship linking the two varieties that was recently ascertained.
\end{abstract}

\section{INTRODUCTION}

Grape aroma compounds are considered quality indexes that influence the wine's sensory expression (Lund \& Bohlmann, 2006). Terpenoids, $C_{13}$-norisoprenoids, benzenoids, aliphatic alcohols (in short aliphatics), esters, methoxypyrazines and sulphur-containing compounds are the main classes of volatiles identified in grapes (Robinson et al., 2014). Several of these compounds are present in grapes in their free and glycosylated forms, and their relative proportion varies according to the cultivar (González-Barreiro et al., 2015). Glycosides are considered an aromatic potential, since they are susceptible to releasing volatile aglycones through enzymatic or acid hydrolysis (Loscos et al., 2009).

It has long been known that terpene compounds contribute mainly to the varietal aromatic profile (Stevens et al., 1966; Webb et al., 1966; Ribéreau-Gayon et al., 1975; Gunata et al., 1985). In fact, aromatic and non-aromatic grapevine varieties can be distinguished on the basis of their total concentration of free monoterpenes (Mateo \& Jiménez,
2000). A different classification of the aromatic varieties can be carried out according to the prevalence of either linalool and its derivatives or geraniol and its derivatives (Di Stefano, 2013).

Malvasia di Candia aromatica (MC) and Malvasia odorosissima (MO; also known as Malvasia aromatica di Parma) are white aromatic varieties belonging to the Malvasia family, a large group of cultivars commonly considered to be born in Greece and widely cultivated in the Mediterranean area (Crespan et al., 2006), as well as North America (Bettiga et al., 2003), South America (Fielden, 2003; Ducati et al., 2009) and Australia.

One of the most interesting aspects of many Malvasia varieties is the expression of aromatic compounds. Just like the Moscato family, Malvasia varieties are used worldwide in winemaking due to their peculiar sensory characteristics. In particular, these kinds of wines are in great demand in the Asian and Eastern markets, where grapevine nurseries and grapevine growing are developing strongly.

\footnotetext{
*Corresponding author: E-mail address: giuseppe.montevecchi@unimore.it [Tel.: +390522523541; Fax: +390522 522027]

Acknowledgements: The authors are grateful to Prof. Alberto Tagliavini (I.T.A., A. Zanelli, Reggio Emilia, Italy), for supplying the grape samples, and to Dr Laura Munari (English language reviewer). Moreover, the authors thank the Bank Foundation, "Cassa di Risparmio di Modena", for the GC-MS (Agilent Technologies) used in the Laboratory of Mass Spectrometry at CIGS at the University of Modena and Reggio Emilia, as well as Dr Diego Pinetti and Dr Filippo Genovese, for their advice and valuable support. This study was funded by the AGER project no. 2010-2014: An Italian Vitis database with multidisciplinary approach, for exploitation and valorisation of the regional genotypes
} 
Malvasia di Candia aromatica and Malvasia odorosissima are particularly interesting, not only as representatives of the Italian grapevine germplasm, but also of the international one. In fact, $\mathrm{MC}$ is a well-known cultivar in the worldwide vine and wine scene, while $\mathrm{MO}$ is almost unknown internationally, although historical records and local tradition attest to its oenological potential, which requires analytical confirmation for targeted exploitation. Known at least since the 19th century in Emilia (Northern Italy), MO is currently on the brink of extinction because of its low productivity, and it has often been replaced in vineyards by the higher yielding MC (Bignami et al., 2015). A recent genetic study (Ruffa et al., 2016) describes a parent-offspring relationship between MO and MC, as well as between MO and White Muscat (Moscato bianco). At the same time, no genetic relationship has been observed between $\mathrm{MC}$ and White Muscat.

The aromatic profiles of MC grapes (Scienza et al., 1989; Borsa et al., 2005; D’Onofrio et al., 2016) and MC wine (Montevecchi et al., 2015) have already been described. However, as far as we know there is no information on the aroma profile of $\mathrm{MO}$ in the literature, except a note reporting that the MO sensory profile is similar to that of the White Muscat grape rather than being a typical aromatic Malvasia grape (Fontana, 2104).

The aim of this study was to provide an aromatic characterisation of $\mathrm{MO}$ and $\mathrm{MC}$ in order to highlight each distinctive aromatic profile and support the use of these varieties for winemaking and product differentiation, thus safeguarding the local biodiversity. The effects of climatic conditions in two consecutive vintages were also considered.

\section{MATERIALS AND METHODS \\ Sampling}

The MO and MC plants were cultivated in contiguous and homogeneous plots of the same germplasm collection located in the Reggio Emilia area (I.T.A. A. Zanelli, latitude $44.675420^{\circ} \mathrm{N}$, longitude $\left.10.584984^{\circ} \mathrm{E}\right)$. Ten bunches in good sanitary condition were collected from three plants of each variety when sugar accumulation (soluble solids) became almost constant - around $21^{\circ}$ Brix. Harvest dates were 2012-09-10 and 2013-09-17. Following collection, the samples were maintained at $4^{\circ} \mathrm{C}$, immediately transferred to the laboratory and quickly subjected to the extraction protocol. Analytical replicates $(n=4$, two per vintage) consisted of one hundred berries picked randomly at the base of the pedicel.

A standard set of 9 microsatellite (SSR) markers was used for the molecular characterization, a useful tool commonly performed to avoid sampling mistakes. All the accessions considered in this work were previously collected and analysed in the framework of a national project devoted to the characterisation of all (major and minor) Italian grapevine varieties (http://www.vitisdb.it).

\section{Soil characteristics and meteorological trends}

The vineyard was grown on a silty clay soil with the following characteristics: sand $10.9 \%$, clay $41.3 \%$, and silt $47.8 \%$. In addition, the $\mathrm{pH}$ was 7.5 and the organic matter was $17.5 \mathrm{~g} / \mathrm{kg}$.
The climatic data was provided by the agrometeorological service of the Emilia Romagna region (ARPAE). Daily datasets of maximum and minimum temperatures and precipitation registered by a weather station located near the vineyard (Cavriago, $8 \mathrm{~km}$ ) were used to calculate the Winkler bioclimatic index and for the evaluation of climate effects on the aroma profile.

\section{Chemicals and standards}

Pure reference compounds, 2-heptanol (internal standard), tartaric acid, sodium metabisulfite $\left(\mathrm{Na}_{2} \mathrm{~S}_{2} \mathrm{O}_{5}\right)$, sodium hydroxide $(\mathrm{NaOH})$, disodium hydrogen phosphate $\left(\mathrm{Na}_{2} \mathrm{HPO}_{4}\right)$ and citric acid were supplied by Fluka-SigmaAldrich $^{\circledR}$ (Milan, Italy). Methanol and dichloromethane were purchased from VWR International Srl (Milan, Italy). Deionised water was obtained using a Milli-Q purification system (Millipore, Milan, Italy).

\section{Extraction of volatiles}

The grape extract was prepared following the methods described by different authors (Di Stefano, 1991; Genovese et al., 2013), with some modifications. In detail, 100 berries (exactly weighed) were peeled and the skins were placed in $20 \mathrm{~mL}$ of methanol for $1 \mathrm{~h}$ in order to deactivate the enzymes and to promote the extraction of the compounds of interest.

Deseeded pulp was collected in a beaker with $100 \mathrm{mg}$ of $\mathrm{Na}_{2} \mathrm{~S}_{2} \mathrm{O}_{5}$ to prevent oxidation, and temporarily kept at $-20^{\circ} \mathrm{C}$ during the time of skin extraction. Then the pulp was added to the methanolic suspension of skins and were ground together and homogenised (Ultra-Turrax, IKA, Germany) after the addition of $20 \mathrm{~mL}$ of a "must-like" tartaric solution at $\mathrm{pH} 3.2$ (tartaric acid $0.5 \% \mathrm{~W} \mathrm{~V}^{-1} ; \mathrm{Na}_{2} \mathrm{~S}_{2} \mathrm{O}_{5} 0.3 \% \mathrm{w} \mathrm{v}^{-1}$; and $\mathrm{NaOH} 1 \mathrm{~N}$ $\left.2.2 \% \mathrm{v} \mathrm{v}^{-1}\right)$. The suspension was centrifuged at $4000 \mathrm{rpm}$ for $15 \mathrm{~min}\left(\right.$ at $\left.4^{\circ} \mathrm{C}\right)$. The supernatant was recovered and the pellet

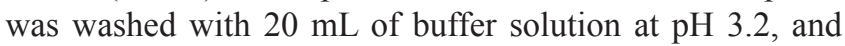
then centrifuged again under the same conditions. The pellet washing was repeated three times, reaching a final extract volume of $250 \mathrm{~mL}$. The obtained extracts were clarified by adding a commercial pectolytic enzyme overnight without side glycosidase activity (Lallzyme HC, Lallemand, Castel d'Azzano, Italy).

Free and glycosylated volatile fractions were isolated by solid phase extraction (SPE), following the method reported by Costa Freitas et al. (2012). Each extract was spiked with $50 \mu \mathrm{L}$ of internal standard (2-heptanol, $1000 \mathrm{mg} / \mathrm{L}$ in ethanol) and eluted through a $5 \mathrm{~g} \mathrm{C}_{18}$-endcapped cartridge (Isolute, Biotage, Uppsala, Sweden), previously activated with $25 \mathrm{~mL}$ of methanol followed by $50 \mathrm{~mL}$ of water. After the sample was loaded, the cartridge was washed with $100 \mathrm{~mL}$ of water in order to remove the hydrophilic compounds. Free aroma compounds were recovered with $50 \mathrm{~mL}$ of dichloromethane.

Glycosylated compounds were subsequently eluted with $30 \mathrm{~mL}$ of methanol. Methanol was eliminated under vacuum in a rotary evaporator (Rotavapor, Büchi, Switzerland) and the residue was dissolved again in $5 \mathrm{~mL}$ of a phosphate-citrate buffer at $\mathrm{pH} 5\left(\mathrm{Na}_{2} \mathrm{HPO}_{4}, 0.2 \mathrm{M} 49.3 \% \mathrm{v} \mathrm{v}^{-1}\right.$; citric acid, 0.1 $\left.\mathrm{M} 50.7 \% \mathrm{~V} \mathrm{v}^{-1}\right)$. To each glycosylated fraction, spiked with 50 $\mu \mathrm{L}$ of internal standard (2-heptanol, $1000 \mathrm{mg} / \mathrm{L}$ in ethanol), a commercial glycosidase enzyme with $\beta$-glycosidase activity (Lallzyme HC, Lallemand, Castel d'Azzano, Italy) was 
added at $40^{\circ} \mathrm{C}$ for $24 \mathrm{~h}$ in order to release the aglycons. This hydrolysed sample was eluted through a $1 \mathrm{~g} \mathrm{C}_{18}$-endcapped cartridge (Isolute, Biotage, Uppsala, Sweden), previously activated with $5 \mathrm{~mL}$ of methanol followed by $10 \mathrm{~mL}$ of water. After being loaded, the cartridge was washed with $10 \mathrm{~mL}$ of water in order to remove the hydrophilic compounds. Free aglycons were recovered with $6 \mathrm{~mL}$ of dichloromethane.

The dichloromethane extracts containing free and glycosylated aroma compounds were first concentrated under vacuum in a rotary evaporator (Rotavapor, Büchi, Switzerland), and then under a gentle nitrogen flow up to about $50 \mu \mathrm{L}$. Finally, the samples were subjected to GC-MS analysis.

\section{GC-MS analysis}

GC-MS analyses were carried out with an Agilent GC-MSD (7890A/5975C, Agilent Technologies Inc., Santa Clara, CA, USA) equipped with an autosampler.

A Stabilwax-DA capillary column $(0.25 \mathrm{~mm}$ i.d. $\times 30 \mathrm{~m}$ length $\times 0.25 \mu \mathrm{m} \mathrm{df}$, Restek, Milan, Italy) was employed using ultrapure helium as carrier gas at a flow rate of $0.9 \mathrm{~mL}$ $\min ^{-1}$. The injector (splitless mode) and the transfer line were set at $240^{\circ} \mathrm{C}$. The oven initial temperature was set at $30^{\circ} \mathrm{C}$. The temperature was increased by $4.25^{\circ} \mathrm{C} \mathrm{min}^{-1}$ up to $230^{\circ} \mathrm{C}$, and then finally held for $20 \mathrm{~min}$ (66 $\mathrm{min}$ in total). The MS ion source operated by electron ionisation (EI) at $150^{\circ} \mathrm{C}$. The ionisation energy was set at $70 \mathrm{eV}$ and the mass range at 33 to $350 \mathrm{~m} / \mathrm{z}$, in full-scan acquisition mode.

Identification was carried out by comparing the retention times and the qualifying ions of all the available pure standards. In the absence of pure standards, the volatiles were tentatively identified by comparing the mass spectra with those present in the data system libraries (Wiley $7^{\text {th }}$ Edition Library and NIST-05a). Whenever it was possible, the presence of volatiles was also verified in the literature focused on similar aromatic varieties. Quantification was carried out by measuring the relative peak area of the quantifying ion in relation to that of the internal standard.

\section{Statistical analysis}

Analysis of variance (two-way ANOVA) was performed using Statistica version 8.0 software (Stat 180 Soft Inc., Tulsa, OK, USA).

\section{RESULTS AND DISCUSSION \\ Free compounds}

Free forms of eleven aliphatics, twenty-four terpenoids, and fourteen benzenoids, and three C13-norisoprenoids were identified and quantified (Table 1).

Two-way ANOVA was applied to the data, considering varieties (MO and MC) and vintages (2012 and 2013) as factors, as well as their interaction (varieties $\times$ vintages). With regard to the varieties, statistically significant differences were found for all the volatiles, except for hexanal, $\beta$-citronellol, benzaldehyde, acetophenone, eugenol, vanillin and acetovanillone.

ANOVA applied to the two vintages showed statistically significant differences for a lower number of compounds (Table 1). In general, in the first year of vintage the mean concentrations of volatiles in $\mathrm{MC}$ were almost double that in the second year for most of the substances. The sum of terpenoids was significantly higher for MO, while the sum of aliphatics and benzenoids was significantly higher for $\mathrm{MC}$.

Interaction effects were significant for the sum ofaliphatics and the sum of terpenoids, while no significant interaction was observed for the sum of benzenoids. 1-Hexanol, (E)-2hexen-1-ol, (Z)-2-hexen-1-ol, $\beta$-citronellol, geraniol, geranic acid and methyl vanillate showed significant interactions between the factors due to lower values in the second vintage for MC. This trend indicated a dependence of $\mathrm{MC}$ on the vintage, while MO did not show the same behaviour.

The relative mean values of the two vintages showed that MO was characterised (Fig. 1A) by a prevalence of total terpenoids $(97.0 \%)$, followed by benzenoids $(1.6 \%)$ and aliphatics $(1.4 \%)$. The relative aromatic profile of the MC (Fig. 1B) highlights a lower terpenoid fraction (70.7\%), along with higher aliphatics $(24.2 \%)$ and benzenoids (5.1\%). With regard to terpenoids (Table 1), both varieties showed a prevalence of geraniol and its derivatives $\left(\mathrm{G}_{\mathrm{GR}}\right)$ that was one order of magnitude higher than linalool and its derivatives $\left(\mathrm{L}_{\mathrm{GR}}\right)$. However, $\mathrm{MO}$ showed comparable amounts of the $c i s$ form of geraniol - nerol - thus partially justifying its name, odorosissima (very fragrant).

The two rose oxide isomers are pleasant volatiles associated with a very low threshold of perception (Table 1). Both of them were only detected in MO, thus supporting a sensory (Fontana, 2014) and a genetic similarity (Ruffa et al., 2016) between MO and White Muscat. Unlike aromatic Malvasia grapes, White Muscat is a variety characterised by both a prevalence of linalool and its derivatives (RibéreauGayon et al., 1975; Di Stefano \& Corino, 1984; Palomo

A

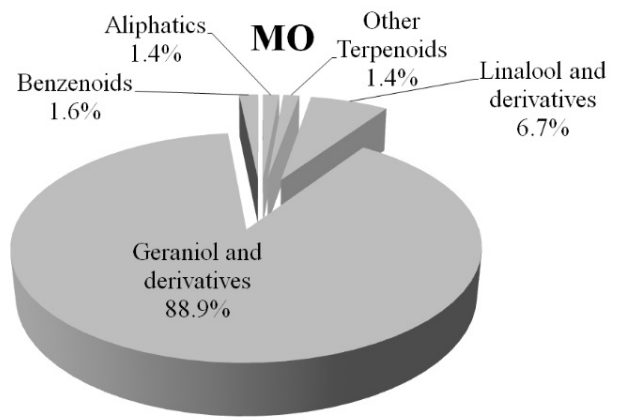

B

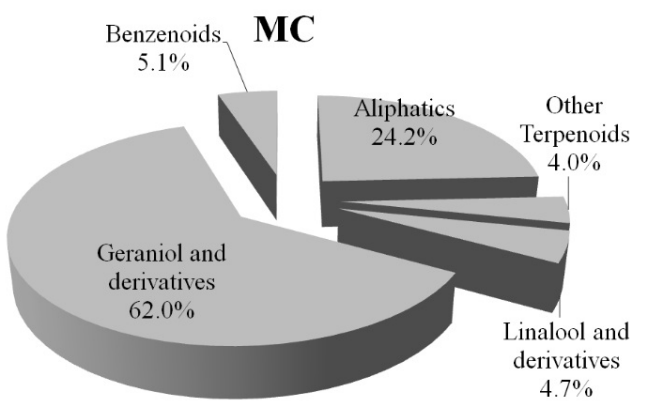

FIGURE 1

Free aroma groups of (A) Malvasia odorosissima (MO) and (B) Malvasia di Candia aromatica (MC). Relative values (\%) calculated as the sum of the mean values of the two vintages. 


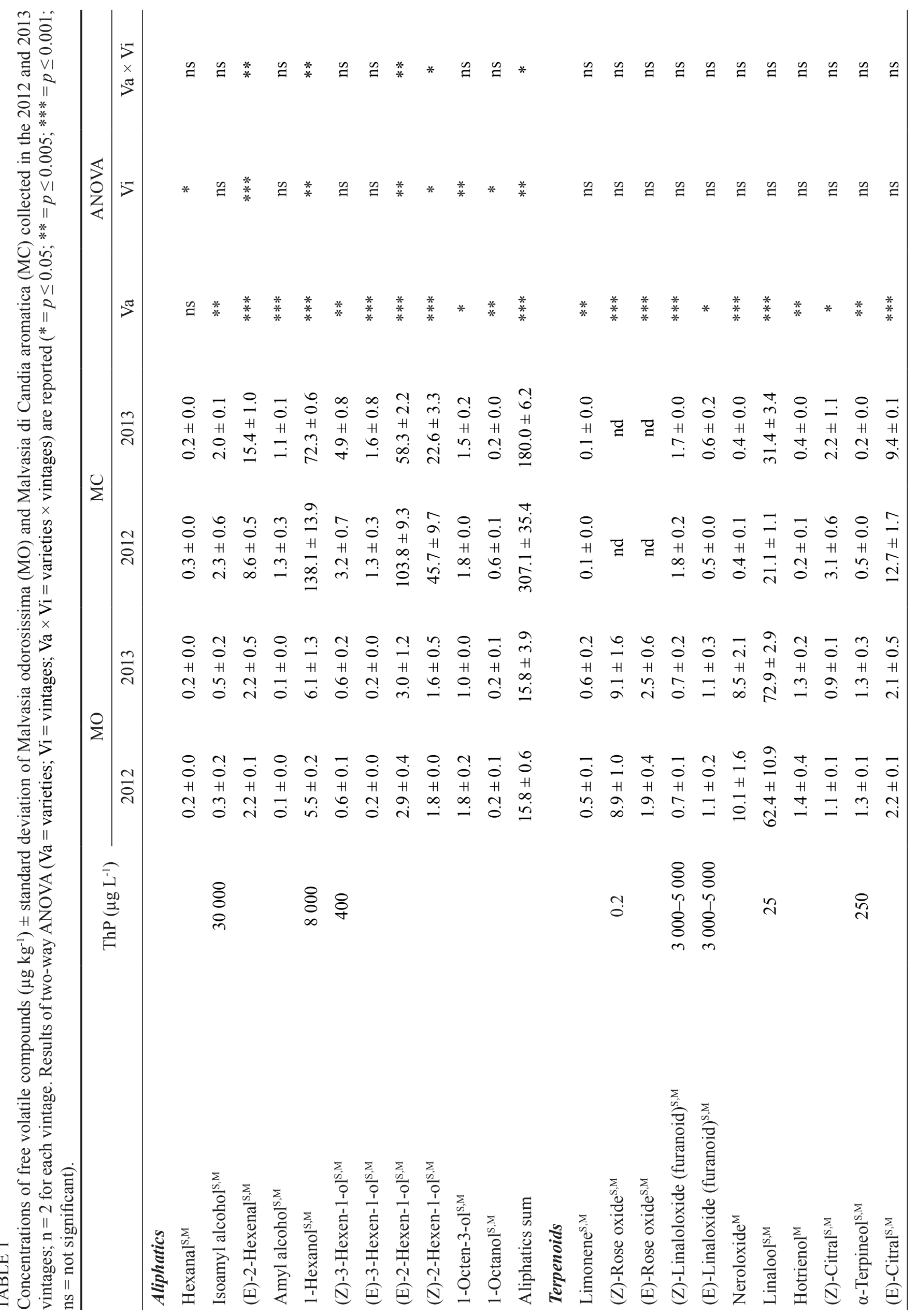




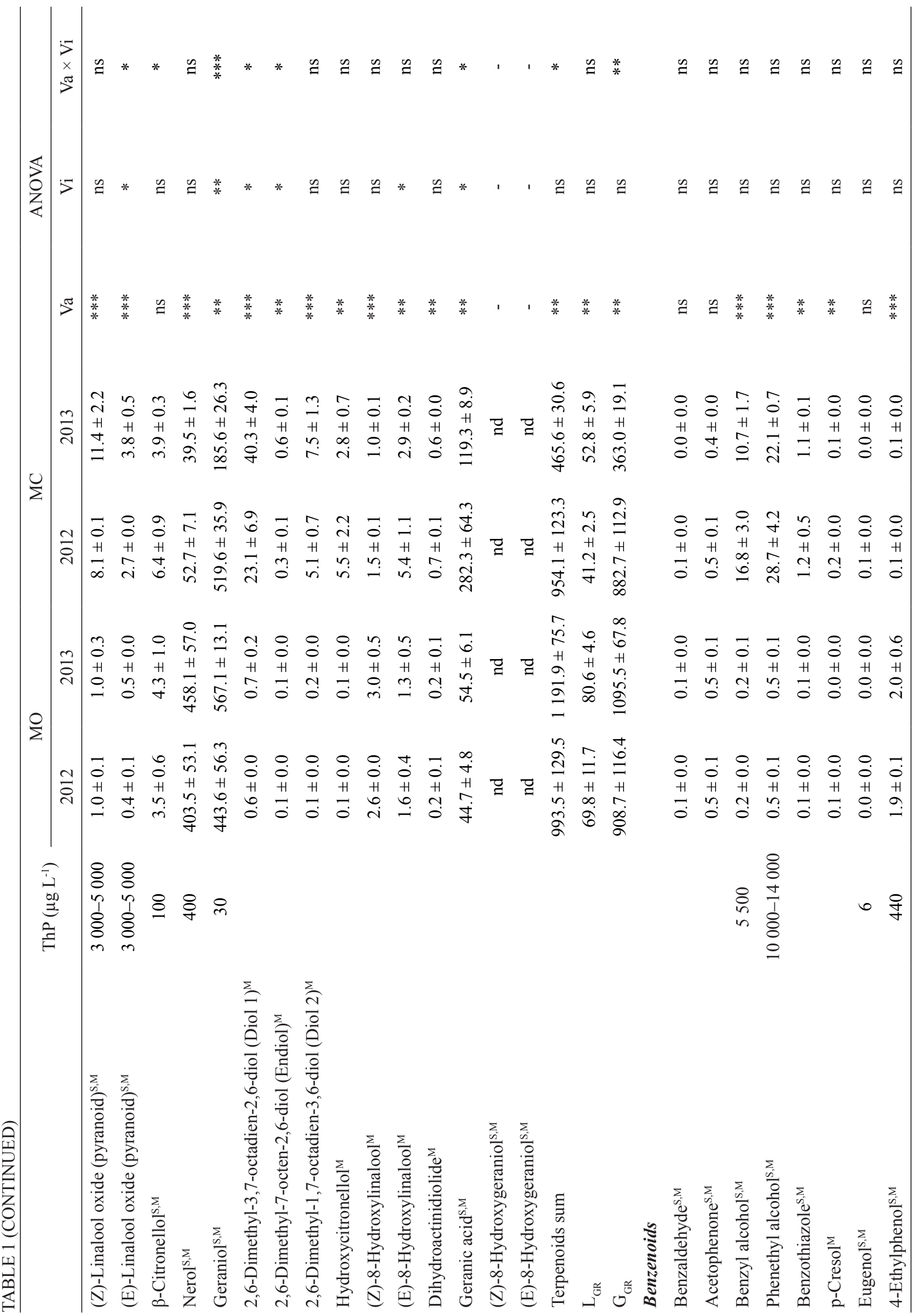




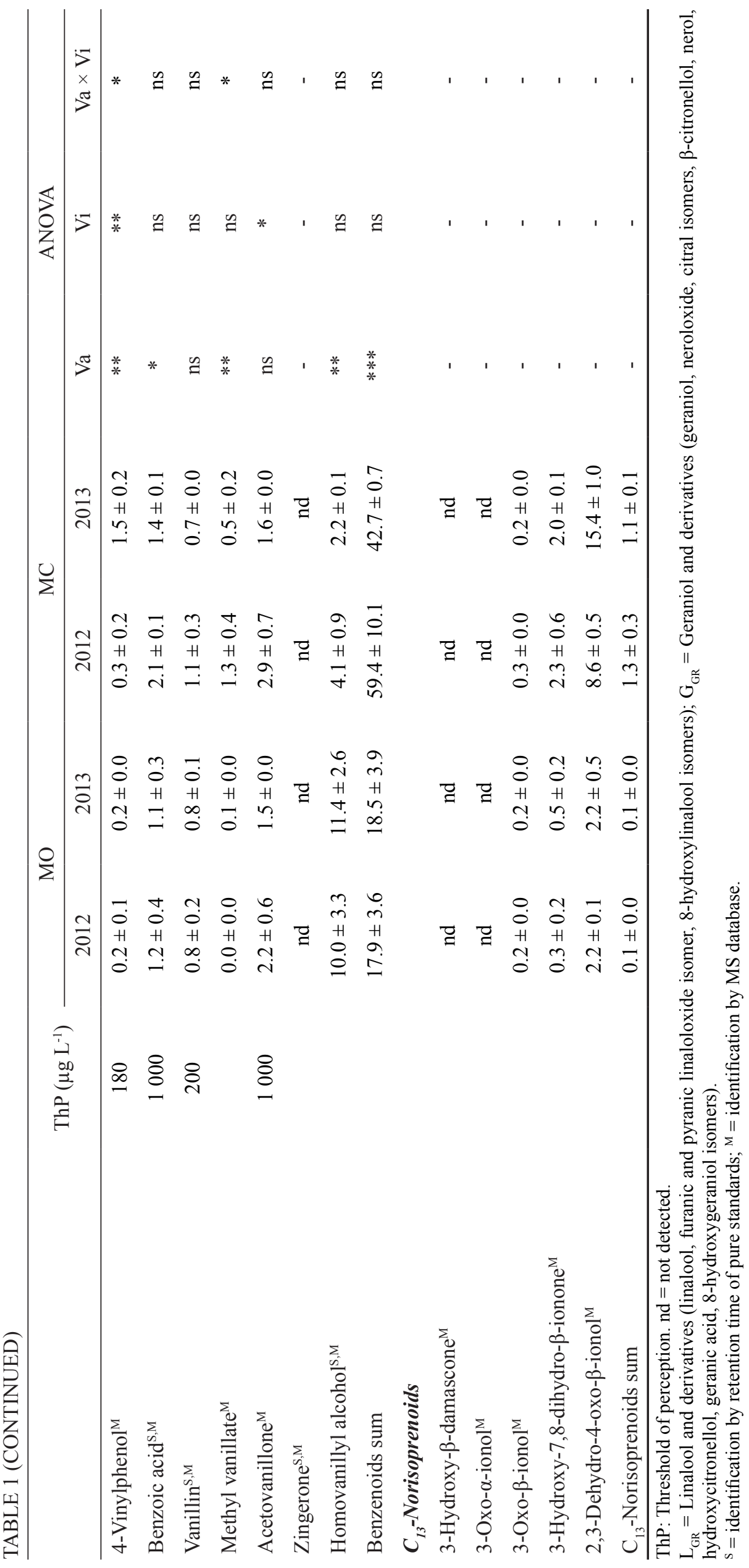




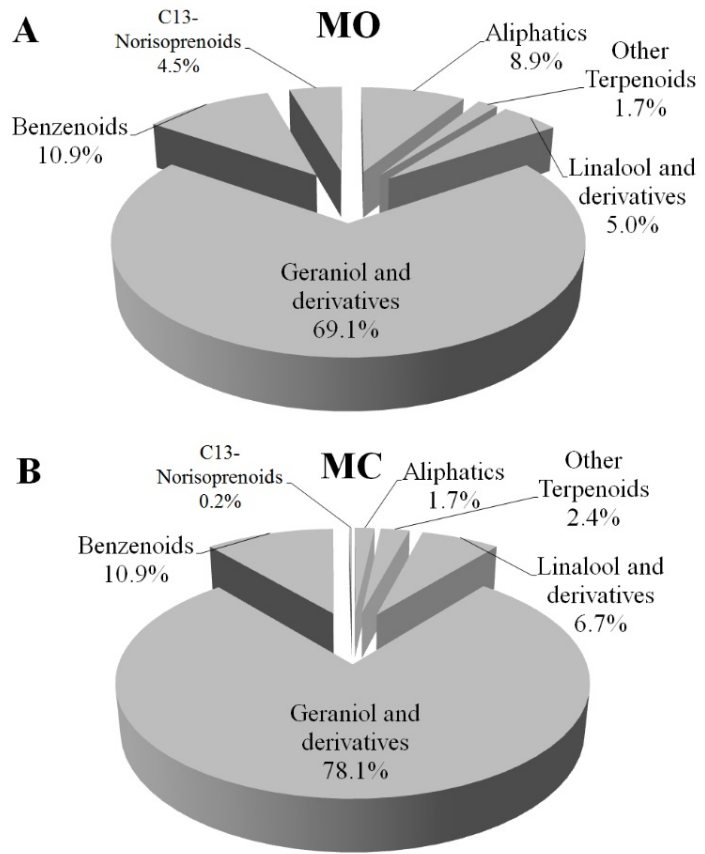

FIGURE 2

Glycosylated aroma groups of (A) Malvasia odorosissima (MO) and (B) Malvasia di Candia aromatica (MC). Relative values $(\%)$ calculated as the sum of the mean values of the two vintages.

et al., 2006) and the presence of rose oxide isomers (RuizGarcía et al., 2014).

Apart from geraniol, the MC terpenoid profile was characterised by diol 1 and diol 2, and their presence was consistent with what was found by Scienza et al. (1989) and D'Onofrio et al. (2016), but it did not agree with what was found by Borsa et al. (2005). Therefore, the presence of rose oxide isomers moves $\mathrm{MO}$ aromatically close to White Muscat grape and distinct from MC.

Limonene, neroloxide, hotrienol, nerol, 4-ethylphenol and homovanillyl alcohol showed concentrations significantly higher in MO than in MC, even though only nerol presented a concentration higher than the threshold of perception. For the sake of precision, it must be noted that this consideration is strictly related to grapes. Winemaking changes the varietal volatile profile deeply. In fact, part of the free fraction is lost through volatilisation, but it has to be replaced by hydrolysis of the glycosylated fraction (Wilson et al., 1986).

(Z)-linalool oxide (pyranoid), (E)-linalool oxide (pyranoid), (E)-citral, (Z)-citral, hydroxycitronellol, (E)-8hydroxylinalool and geranic acid showed a concentration significantly higher in MC then in MO. In particular, citral had a low threshold of perception and was associated with a lemon scent.

MC showed high concentrations of most of the aliphatics. In particular, the concentration of the alcohols with six carbon atoms (C6 alcohols), 1-hexanol, (Z)-3hexen-1-ol, (E)-2-hexen-1-ol and (Z)-2-hexen-1-ol, as well as (E)-2-hexenal, was by far higher in MC than in MO. C6 alcohols are substances of pre-fermentative origin and may provide a herbaceous scent.

Phenethyl and benzyl alcohol presented a concentration significantly higher $(p<0.001)$ in MC than in MO. Both of them are varietal volatiles with a pleasant floral note of rose. Only phenethyl alcohol is also a fermentative volatile, arising from amino acid microbial metabolism (Gómez-Plaza et al., 1999), and the varietal amount represents a low contribution to the total concentration in the fermented products.

\section{Glycosylated compounds}

Glycosylated forms of 11 aliphatics, 25 terpenoids, 15 benzenoids and five $\mathrm{C}_{13}$-norisoprenoids were identified and quantified (Table 2).

Two-way ANOVA was applied to this dataset, considering variety (MO and MC) and vintage (2012 and 2013) as factors, as well as their interaction. ANOVA(between varieties) showed statistically significant differences for all the volatiles, except for (E)-2-hexanal, (Z)-3-hexen-1ol, 1-octen-3-ol, benzaldehyde, vanillin, 3-oxo- $\beta$-ionol and 3-hydroxy-7,8-dihydro- $\beta$-ionone.

The concentration of most of the volatiles was significantly higher in $\mathrm{MC}$ than in $\mathrm{MO}$, with a few exceptions. Among the C6 alcohols, (Z)-2-hexen-1-ol showed higher concentrations $(p<0.001)$ in MO than in MC. (Z)-Rose oxide and endiol were present only in $\mathrm{MO}$, albeit at lower concentrations in comparison with the free forms of the same variety. Acetophenone $(\mathrm{p}<0.001)$, 4-ethylphenol, benzoic acid and homovanillyl alcohol showed significant higher concentrations in $\mathrm{MO}$. Finally, two $\mathrm{C}_{13}$-norisoprenoids, 3-oxo- $\alpha$-ionol and 2,3-dehydro-4-oxo- $\beta$-ionol, were significantly higher in $\mathrm{MO}$.

ANOVA applied to the vintages showed a higher number of significant differences in comparison with what found in the free aroma compounds, mostly due to the lower concentrations found for $\mathrm{MC}$ in the second vintage. Interaction effects were significant for the sum of terpenoids, the sum of benzenoids and the sum of $\mathrm{C}_{13}$-norisoprenoids, while no significant interaction was observed for the sum of aliphatics. Once again, significant interactions between the factors were due to the lower concentration of a large part of volatiles in the second vintage for $\mathrm{MC}$.

MO (Fig. 2A) and MC (Fig. 2B) were both characterised by the prevalence of total terpenoids $(75.8 \%$ and $87.2 \%$ respectively), followed by benzenoids $(10.9 \%$ for both), aliphatics $\left(8.9 \%\right.$ and $1.7 \%$ respectively), and $\mathrm{C}_{13}$ norisoprenoids ( $4.9 \%$ and $0.2 \%$ respectively).

For both varieties, the $\mathrm{G}_{\mathrm{GR}}$ content was one order of magnitude higher than that of $\mathrm{L}_{\mathrm{GR}}$, as already observed for the free aroma compounds.

In terms of absolute concentrations, MO showed a considerably lower content for all groups of compounds, except for $\mathrm{C}_{13}$-norisoprenoids, in comparison to $\mathrm{MC}$ (Table 2). This point represents a major distinguishing factor between the two varieties. As a matter of fact, MC showed a terpenoid content in the glycosylated form that was more than three times higher than in the free form and even higher for benzenoids, so that these scentless precursors may act as a reservoir of flavour (Del Caro et al., 2014). For this reason, $\mathrm{MC}$ has a high latent aromatic potential. On the other hand, MO showed a content of benzenoids very similar for the 


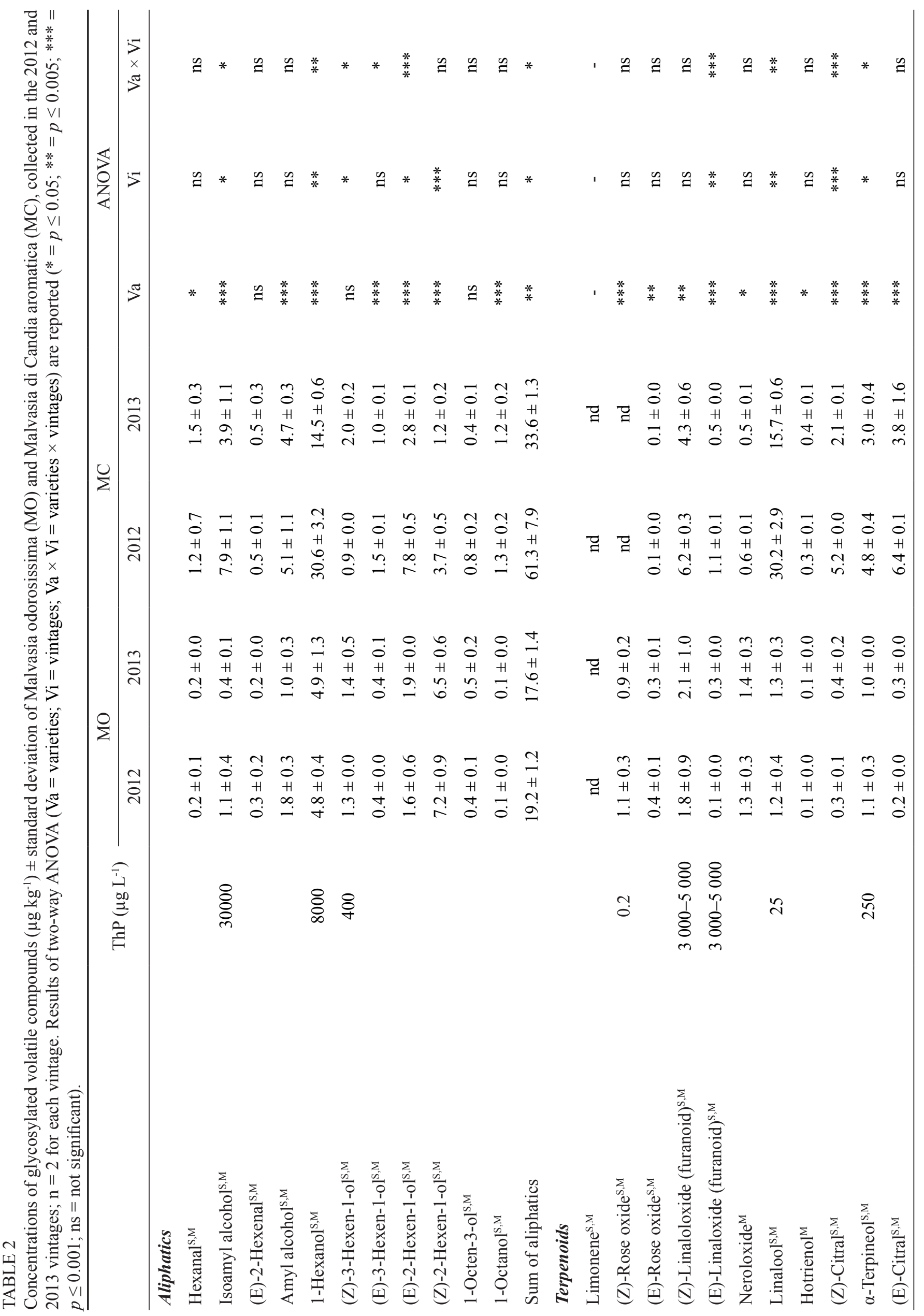




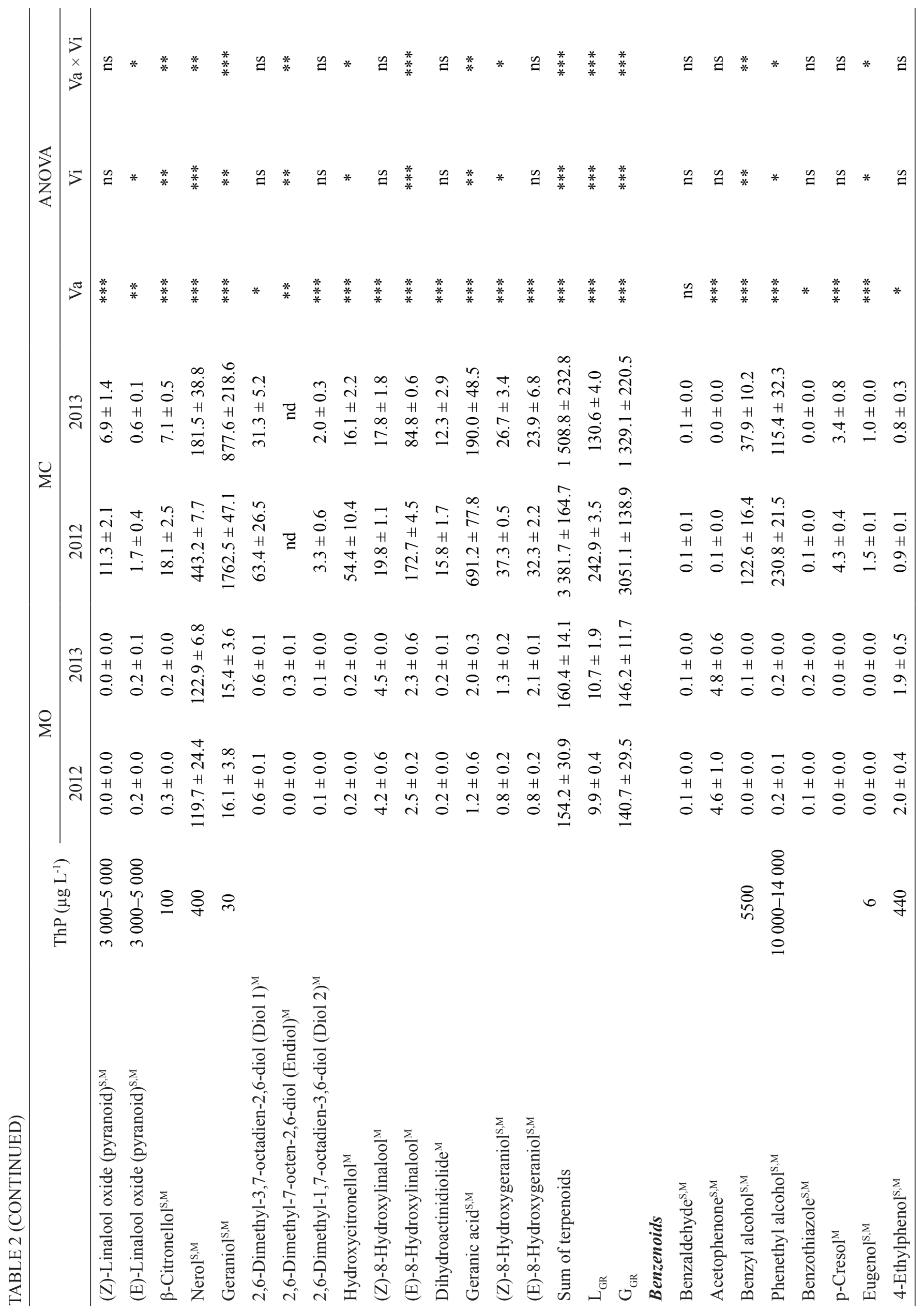




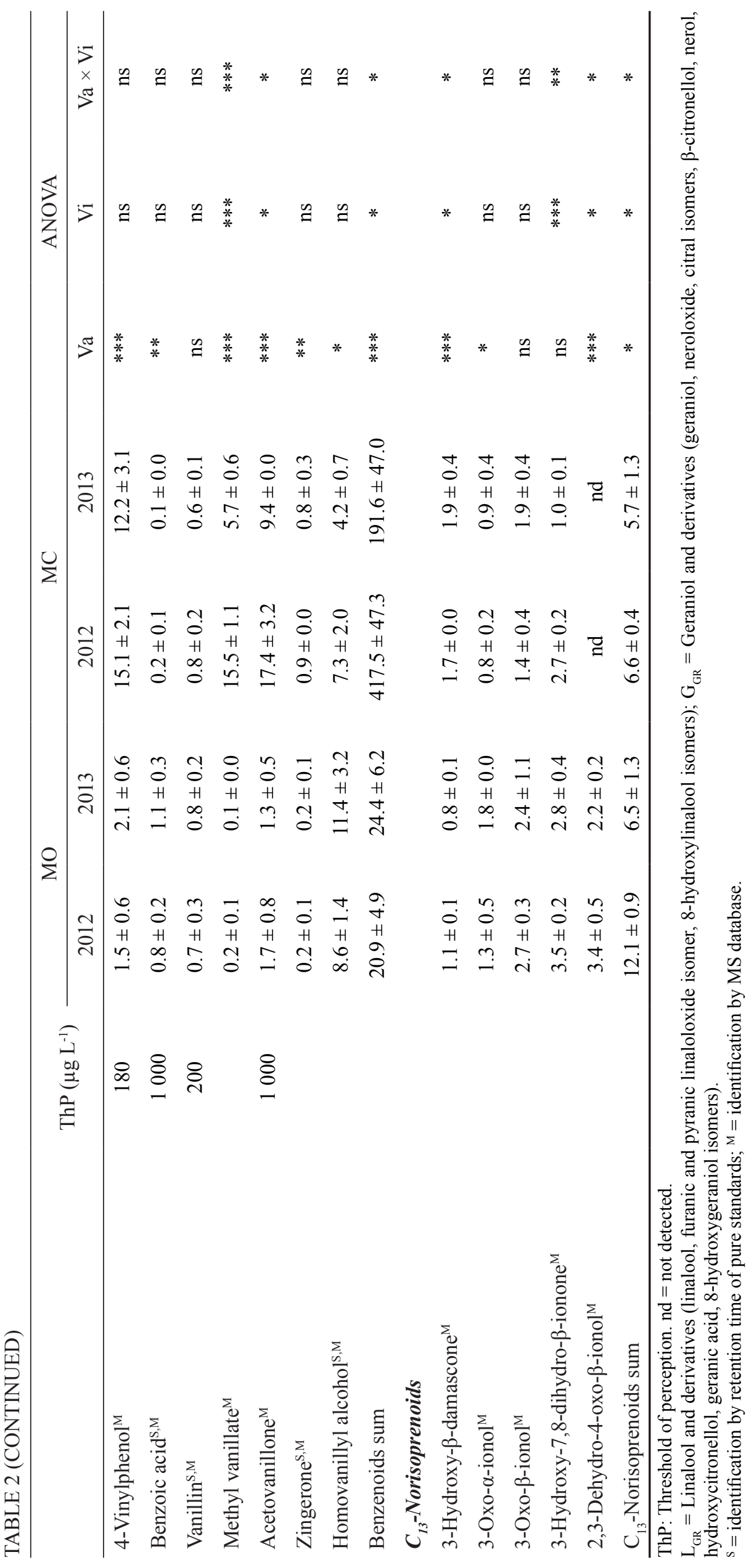


free and glycosylated forms, and a content of glycosylated terpenoids one order of magnitude lower than that of the free form. In contrast to $\mathrm{MC}, \mathrm{MO}$ is proven to express its aromatic patrimony almost completely and presents a very small amount of volatiles in the glycosylated form.

The lack of glycosylated terpenoids observed in $\mathrm{MO}$ was not consistent with what was reported for other aromatic grapes, i.e. a terpenoid glycosylated fraction more abundant than the free one (Selli et al., 2003; González-Barreiro et al., 2015).

\section{Relationship between aromatic profile and climatic conditions}

The year 2012 was characterized by low rainfall $(700 \mathrm{~mm})$ and a quite warm summer season $\left(24.8^{\circ} \mathrm{C}\right.$ seasonal average temperature; $38.9{ }^{\circ} \mathrm{C}$ maximum seasonal temperature). In the year 2013 the summer was cooler, with a mean and maximum seasonal temperature of $23.4{ }^{\circ} \mathrm{C}$ and $37.2{ }^{\circ} \mathrm{C}$, and the annual rainfall was higher than in the previous year (989 mm). The Winkler index (WI April-October) was 2038 in 2012 and 1928 in 2013.

In $\mathrm{MC}$, the warmer and drier weather conditions of the first year were conducive to increasing the production of volatile substances in both the free and glycosylated forms, compared to in the second year (Ribéreau-Gayon et al., 2006). However, the ratio between free and bounded forms remained practically unchanged over the two years, with only a few exceptions.

The concentration of free (E)-2-hexenal in MC was higher in the second, cooler vintage. Some authors have reported higher concentrations of 6-carbon aldehydes, including (E)-2-hexenal, in grapes grown in a cool site than those grown in a hotter site (Ji \& Dami, 2008; Fang \& Qian, 2012; Xu et al., 2015). The same trend was not showed by hexanal because of its tiny concentration in the samples, or by glycosylated (E)-2-hexenal.

In contrast to the main terpenols (i.e. geraniol and nerol) in $\mathrm{MC}$, the free form of linalool was present in higher concentrations in the samples harvested in the second, cooler vintage. Monoterpenes are sensitive to environmental conditions. Most of them accumulate in hot climatic conditions, with linalool as the only exception (Reynolds et al., 1996; Ji \& Dami, 2008; Song et al., 2015). Linalool biosynthesis includes the action of a decarboxylase, which is more sensitive to sun exposure than other enzymes (Belancic et al., 1997), whereas geraniol, nerol, citronellol and other monoterpenes are synthetised through a different pathway.

\section{Technological considerations}

The outcomes obtained are very interesting from a technological standpoint. In fact, terpenoid free forms are key compounds, as they are the aromatic impact substances in grapes, as well as in their derivate products - must and wines. However, they tend to be stripped by developing $\mathrm{CO}_{2}$ during alcoholic fermentation. In contrast, the glycosylated forms act as a buffer, as they are slowly released during fermentation and storage (Wilson et al., 1986). Moreover, the presence of high quantities of glycosylated terpenols justifies and suggests the use of cold maceration techniques, such as the "criomaceration" (Amati et al., 1982) or the more recent "pellicular maceration" (Baumes et al., 1988), already applied to Malvasia di Candia aromatica (Montevecchi et al., 2015) to enhance the extraction of the sugar-linked forms, particularly soluble in must.

\section{CONCLUSIONS}

The increasing interest in Malvasia wines on the international market opens good prospects to re-propose the diversification of oenological products from the underexploited Malvasia cultivars.

The richness of the aromatic profile of MO is an important feature for the oenological exploitation of this variety, which is currently on the brink of extinction and erroneously confused with MC, even by winemakers. The peculiarity of the volatile profile, with a high content of terpenoids in the free form - even higher than in $\mathrm{MC}$, provides a prerequisite for the production of aromatic wines. In addition, MO seems to be less susceptible to seasonal variation in terms of the quantitative expression of volatiles, as otherwise shown by MC. This supposed stability is of considerable interest and deserves further investigation in the current situation of climate change, which is affecting grape and wine quality.

Some evidence renders the MO aromatic profile similar to that of White Muscat, thus giving value to the proximity already demonstrated by the genetic analysis between the two aromatic varieties.

The low yield of this cultivar, which was the only reason for its substitution in the vineyards with the high-yielding $\mathrm{MC}$, may be overcome or mitigated by agronomic tools aimed at enhancing the poor fruit set of its female flowers through the introduction of appropriate pollinisers and canopy management in the vineyard.

\section{LITERATURE CITED}

Amati, A., Carnacini, A., Monti, R., Riponi, C. \& Zironi, R., 1982. Vinificazione a temperatura controllata; influenza del tempo e della temperatura in un impianto pilota. Vignevini 9(10), 2935.

Baumes, R., Bayonove, C., Barillere, J.M., Escudier, J.L. \& Cordonnier, R., 1988. La macération pelliculaire dans la vinification en blanc. Incidence sur la composante volatile des moûts. J. Int. Sci. Vigne Vin 22, 209223.

Belancic, A., Agosin, E., Ibacache, A., Bordeu, E., Baumes, R., Razungles, A. \& Bayonove, C., 1997. Influence of sun exposure on the aromatic composition of Chilean Muscat grape cultivars Moscatel de Alejandria and Moscatel rosada. Am. J. Enol. Vitic. 48, 181-186.

Bettiga, L.J., Christensen, L.P., Dokoozlian, N.K., Golino, D.A., McGourty, G., Smith, R.J., Verdegaal, P.S., Walker, M.A., Wolpert, J.A. \& Weber, E., 2003. Wine grape varieties in California. University of California Agricultural and Natural Resources (publication no. 3419), Oakland.

Bignami, C., Imazio, S., Antonelli, A., Masino, F., Matrella, V., Montevecchi, G. \& Vasile-Simone, G., 2015. Malvasia odorosissima. Italian Vitis Database [Online]: http://www.vitisdb.it/varieties/show/1474 [accessed on 08 April 2017]

Borsa, D., Carniel, D., Asproudi, A., Monticelli, L., Crespan, M. \& Costacurta, A., 2005. Caratterizzazione di uve Malvasia attraverso lo studio dei metaboliti secondari. Rivista di Viticoltura e di Enologia 58(2), 167182.

Costa Freitas, A.M., Gomes da Silva, M.D.R. \& Cabrita, M.J., 2012. Sampling techniques for the determination of volatile components in grape juice, wine and alcoholic beverages. In: Pawliszyn, J. (ed.). Comprehensive sampling and sample preparation. Academic Press (Elsevier), Oxford (UK). 
Crespan, M., Cabello, F., Giannetto, S., Ibáñez, J., Karoglan Kontić, J.K., Maletić, E., Pejić, I. Rodríguez-Torres, J. \& Antonacci, D. (2006). Malvasia delle Lipari, Malvasia di Sardegna, Greco di Gerace, Malvasia de Sitges and Malvasia dubrovacka - Synonyms of an old and famous grape cultivar. Vitis 45(2), 69-73.

Del Caro, A., Piombino, P., Genovese, A., Moio, L., Fanara, C. \& Piga, A., 2014. Effect of bottle storage on colour, phenolics and volatile composition of Malvasia and Moscato white wines. S. Afr. J. Enol. Vitic. 35, 128138.

Di Stefano, R., 1991. Proposition d'une méthode de préparation de l'échantillon pour la détermination des terpènes libres et glycosides des raisins et des vins. Bulletin de l'OIV 64, 219223.

Di Stefano, R., 2013. Gli aromi dei Moscati con particolare riferimento a quelli del Moscato Giallo. Atti dell'Accademia Italiana della Vite e del Vino [Online]: http://aivv.it/Archivio/Atti/R053 1309 1055 DiStefano.pdf [accessed on 28 June 2017].

Di Stefano, R. \& Corino, L., 1984. Terpeni ed antociani di alcuni uve rosse aromatiche. Annali dell'Istituto Sperimentale per la Viticoltura, Conegliano Veneto.

D’Onofrio, C., Matarese, F. \& Cuzzola, A., 2016. Study of the terpene profile at harvest and during berry development of Vitis vinifera L. aromatic varieties Aleatico, Brachetto, Malvasia di Candia aromatica and Moscato bianco. J. Sci. Food Agric. doi:10.1002/jsfa.8126

Ducati, J.R., Bettú, V. \& Hoff, R., 2009. Remote sensing techniques in the characterization of viticultural terroirs in South Brazil: A case study on Malvasia. In: Proc. 3rd International Symposium Malvasia 23-27 May, Santa Cruz de Tenerife, Spain. pp. $1-18$.

Fang, Y. \& Qian, M.C., 2012. Development of C6 and other volatile compounds in Pinot Noir grapes determined by Stir Bar Sorptive ExtractionGC-MS. In: Flavor chemistry of wine and other alcoholic beverages. ACS Symposium Series. American Chemical Society, Washington DC. pp. 81 -99 .

Fielden, C., 2003. The wines of Argentina, Chile and Latin America. Hachette UK, London.

Fontana, M., 2014. Agrobiodiversità vegetale, Regione Emilia-Romagna [Online]: http://agricoltura.regione.emilia-romagna.it/agrobiodiversita/doc/ agrobiodiversita-vegetale [accessed on 28 June 2017].

Genovese, A., Gambuti, A., Lamorte, S.A. \& Moio, L., 2013. An extract procedure for studying the free and glycosilated aroma compounds in grapes. Food Chem. 136, 822834.

Gómez-Plaza, E., Gil-Muñoz, R., Carreño-Espín, J., Fernández-López, J.A. \& Martínez-Cutillas, A., 1999. Investigation on the aroma of wines from seven clones of Monastrell grapes. Eur. Food Res. Technol. 209, 257260.

González-Barreiro, C., Rial-Otero, R., Cancho-Grande, B. \& Simal-Gándara, J., 2015. Wine aroma compounds in grapes: A critical review. Crit. Rev. Food Sci. 55, 202218

Gunata, Y.Z., Bayonove, C.L., Baumes, R.L. \& Cordonnier, R.E., 1985. The aroma of grapes I. Extraction and determination of free and glycosidically bound fractions of some grape aroma components. J. Chromatogr. A 331, 8390 .

Ji, T. \& Dami, I.E., 2008. Characterization of free flavor compounds in Traminette grape and their relationship to vineyard training system and location. J Food Sci. 73, C262 C267.

Loscos, N., Hernández-Orte, P., Cacho, J. \& Ferreira, V., 2009. Comparison of the suitability of different hydrolytic strategies to predict aroma potential of different grape varieties. J. Agric. Food Chem. 57, 24682480.
Lund, S.T. \& Bohlmann, J., 2006. The molecular basis for wine grape quality - A volatile subject. Science 311, 804805 .

Mateo, J. \& Jiménez, M., 2000. Monoterpenes in grape juice and wines. J. Chromatogr. A 881, 557567.

Montevecchi, G., Masino, F., Vasile Simone, G., Cerretti, E. \& Antonelli, A., 2015. Aromatic profile of white sweet semi-sparkling wine from Malvasia di Candia aromatica grapes. S. Afr. J. Enol. Vitic. 36, 267276.

Palomo, E.S., Pérez-Coello, M.S., Díaz-Maroto, M.C., Viñas, M.A.G. \& Cabezudo, M.D., 2006. Contribution of free and glycosidically-bound volatile compounds to the aroma of muscat "a petit grains" wines and effect of skin contact. Food Chem. 95, 279289.

Reynolds, A.G., Wardle, D.A. \& Dever, M., 1996. Vine performance, fruit composition, and wine sensory attributes of Gewürztraminer in response to vineyard location and canopy manipulation. Am. J. Enol. Vitic. 47, 7792.

Ribéreau-Gayon, P., Boidron, J.N. \& Terrier, A., 1975 Aroma of Muscat grape varieties. J. Agric. Food Chem. 23, 10421047.

Ribéreau-Gayon, P., Dubourdieu, D., Donèche, B. \& Lovaud, A., 2006 ( $2^{\text {nd }}$ ed). The grape and its maturation. In: The handbook of enology, vol I; The microbiology of wine and vinifications. John Wiley and Sons, Chichester UK. pp. $256-259$.

Robinson, A.L., Boss, P.K., Solomon, P.S., Trengove, R.D., Heymann, H $\&$ Ebeler, S.E., 2014. Origins of grape and wine aroma. Part 1. Chemical components and viticultural impacts. Am. J. Enol. Vitic. 65, 124.

Ruffa, P., Raimondi, S., Boccacci, P., Abbà, S. \& Schneider, A., 2016. The key role of "Moscato bianco" and "Malvasia aromatica di Parma" in the parentage of traditional aromatic grape varieties. Tree Genet. Genomes 12(3), 114

Ruiz-García, L., Hellín, P., Flores, P. \& Fenoll, J., 2014. Prediction of Muscat aroma in table grape by analysis of rose oxide. Food Chem. 154, 151157.

Scienza, A., Versini, G. \& Mattivi, F., 1989. Il profilo aromatico ed antocianico dell uva e del vino di Moscato rosa. Atti dell'Accademia Italiana della Vite e del Vino 41, 159181.

Selli, S., Cabaroglu, T., Canbas, A., Erten, H. \& Nurgel, C., 2003. Effect of skin contact on the aroma composition of the musts of Vitis vinifera L. cv. Muscat of Bornova and Narince grown in Turkey. Food Chem. 81, 341347.

Song, J., Smart, R., Wang, H., Dambergs, B., Sparrow, A. \& Qian, M.C., 2015. Effect of grape bunch sunlight exposure and UV radiation on phenolics and volatile composition of Vitis vinifera L. cv. Pinot noir wine. Food Chem. 173, 424431

Stevens, K.L., Bomben, J., Lee, A. \& Mcfadden, W.H., 1966. Volatiles from grapes. Muscat of Alexandria. J. Agric. Food Chem. 14, 249252.

Webb, A.D., Kepner, R.E. \& Maggiora, L., 1966. Gas chromatographic comparison of volatile aroma materials extracted from eight different Muscat-flavored varieties of Vitis vinifera. Am. J. Enol. Vitic. 17, 247254.

Wilson, B., Strauss, C.R. \& Williams, P.J., 1986. The distribution of free and glycosidically-bound monoterpenes among skin, juice, and pulp fractions of some white grape varieties. Am. J. Enol. Vitic. 37, 107111.

Xu, X.Q., Liu, B., Zhu, B.Q., Lan, Y.B., Gao, Y., Wang, D., Reeves, M.J. \& Duan, C.Q., 2015. Differences in volatile profiles of Cabernet Sauvignon grapes grown in two distinct regions of China and their responses to weather conditions. Plant Physiol. Bioch. 89, 123133. 